\title{
Anne-Marie Mamontoff et Jean-Michel Hoerner, Pour une nouvelle recherche en tourisme
}

coll. Homo Touristicus, éd. Balzac, décembre 2009, 138 pages

\section{Philippe Violier}

\section{OpenEdition}

\section{Journals}

Édition électronique

URL : http://journals.openedition.org/tourisme/332

DOI : $10.4000 /$ tourisme.332

ISSN : 2492-7503

\section{Éditeur}

Éditions touristiques européennes

Édition imprimée

Date de publication : 1 juin 2010

Pagination : 85

ISSN : 2109-5671

\section{Référence électronique}

Philippe Violier, « Anne-Marie Mamontoff et Jean-Michel Hoerner, Pour une nouvelle recherche en tourisme », Mondes du Tourisme [En ligne], 1 | 2010, mis en ligne le 30 septembre 2015, consulté le 22 septembre 2020. URL : http://journals.openedition.org/tourisme/332 ; DOI : https://doi.org/10.4000/ tourisme.332

Ce document a été généré automatiquement le 22 septembre 2020.

\section{c) $(1) \ominus$}

Mondes du tourisme est mis à disposition selon les termes de la licence Creative Commons Attribution - Pas d'Utilisation Commerciale - Pas de Modification 4.0 International. 


\title{
Anne-Marie Mamontoff et Jean- Michel Hoerner, Pour une nouvelle recherche en tourisme
}

\author{
coll. Homo Touristicus, éd. Balzac, décembre 2009, 138 pages
}

Philippe Violier

\section{RÉFÉRENCE}

Anne-Marie Mamontoff et Jean-Michel Hoerner, Pour une nouvelle recherche en tourism, coll. "Homo Touristicus", éd. Balzac, 2009.

1 Nous nous attendions, en abordant la lecture de cet ouvrage, à une mise au point argumentée de la pertinence de l'émergence d'une science du tourisme, par l'auteur de Traité de tourismologie. Pour une reconnaissance du tourisme, après notamment le dossier que la revue Téoros a consacré à la même question en 2008 (dossier "Une science du tourisme", vol. 27, $\mathrm{n}^{\circ} 1$, printemps 2008). Comme il se trouve que nous n'avons pas d'idée bien arrêtée sur cette question et que nous avons contribué à un texte (publié dans le revue Téoros citée) qui n’y répond pas de manière tranchée mais énumère plutôt les conditions d'une telle émergence, nous étions nécessairement très intéressé par cet ouvrage. Or cet ouvrage n'apporte rien au débat, voire il contribue à ridiculiser la cause défendue par ses auteurs.

2 Le PREMIER CHAPITRE, titré pompeusement "la science du tourisme", met bout à bout quelques réflexions à l'emporte-pièce pour aboutir à proposer un champ privilégié, "le tourisme international", comme objet d'étude. Certes nous partageons les réticences exprimées par l'auteur à reprendre sans analyse la définition du tourisme proposée par l'OMT mais, d'une part l'auteur enfonce des portes ouvertes (la littérature non citée abonde sur ces questions) et, d'autre part, en quoi est-il plus pertinent de se limiter au tourisme international, lequel bien sûr est défini par l'OMT, puisque c'est justement le champ d'action de cette organisation? Comment justifier de rejeter une définition pour 
ensuite la réactiver? De même, l'auteur s'appuie sur le concept de station qui n'est ni spécifique au tourisme international, ni le seul lieu touristique (mais, pour cela, il faudrait lire et citer les travaux des autres et pas seulement les siens). S'il était pertinent de donner à cette science un objet, l'argumentation n'est pas à la hauteur des enjeux. Ensuite, cela ne suffit pas pour promouvoir la création d'une "nouvelle recherche", car la finalité d'une science est bien de contribuer à la compréhension du monde. Nous doutons qu'avec une telle confusion quelque progrès puisse être accompli dans ce sens.

Le SECOND CHAPITRE, sous l'appellation de "géopolitique du tourisme", aborde successivement, de manière superficielle et dans la confusion la plus totale, quelques questions. Ainsi, le passage sur les migrations, qui procède largement par analogie, constitue un morceau d'anthologie et pourra servir aux universitaires à illustrer auprès de leurs étudiants ce qu'il convient d'éviter pour aboutir à une pensée claire et structurée. Les auteurs n'expliquent pas le lien avec le chapitre précédent : la science du tourisme serait-elle une géopolitique?

4 Le TROISIÈME CHAPITRE n'est guère d'un niveau plus soutenu. L'écriture journalistique continue de mener la plume d'un auteur qui, visiblement, ne contrôle plus rien et passe du coq à l'âne. Un rapide survol de la maigre bibliographie confirme la confusion qui règne dans l'esprit de l'auteur du chapitre ; les articles de presse côtoyant les ouvrages scientifiques, au demeurant peu nombreux, et les références qui "classent" (Durkheim ou Nietzsche).

5 Le QUATRIÈME CHAPITRE, sans doute dû à Anne-Marie Mamontoff, esquisse un programme de recherche qui n'est pas sans intérêt et qui confirme, par contraste, l'impression de collage et de superficialité de l'ensemble : enfin, on peut lire ici un passage un peu construit. Cependant, le lien n'est pas établi avec le tourisme, pas plus qu'avec le tourisme international censé constituer l'objet de la "nouvelle science".

La CONCLUSion est tout simplement pitoyable. L'auteur y annonce qu'il n'a pas l'intention de révolutionner la recherche en tourisme - enfin un peu de clairvoyance ! -, et que l'intention principale de l'ouvrage est "de montrer que des enseignantschercheurs attachés à leurs formations considèrent que leurs étudiants doivent s'inscrire dans une réelle perspective universitaire, où la recherche ne doit pas être un vain mot". Rarement une affirmation n'a été autant contredite par celui qui l'énonce.

\section{AUTEURS}

\section{PHILIPPE VIOLIER}

UMR CNRS Espaces et Sociétés 